\title{
Skeletal muscle mitochondrial uncoupling, adaptive thermogenesis and energy expenditure
}

Citation for published version (APA):

van den Berg, S. A., van Marken Lichtenbelt, W. D., van Dijk, K., \& Schrauwen, P. (2011). Skeletal muscle mitochondrial uncoupling, adaptive thermogenesis and energy expenditure. Current Opinion in Clinical Nutrition and Metabolic Care, 14(3), 243-249. https://doi.org/10.1097/MCO.0b013e3283455d7a

Document status and date:

Published: 01/05/2011

DOI:

10.1097/MCO.0b013e3283455d7a

Document Version:

Publisher's PDF, also known as Version of record

\section{Please check the document version of this publication:}

- A submitted manuscript is the version of the article upon submission and before peer-review. There can be important differences between the submitted version and the official published version of record. People interested in the research are advised to contact the author for the final version of the publication, or visit the DOI to the publisher's website.

- The final author version and the galley proof are versions of the publication after peer review.

- The final published version features the final layout of the paper including the volume, issue and page numbers.

Link to publication

\footnotetext{
General rights rights.

- You may freely distribute the URL identifying the publication in the public portal. please follow below link for the End User Agreement:

www.umlib.nl/taverne-license

Take down policy

If you believe that this document breaches copyright please contact us at:

repository@maastrichtuniversity.nl

providing details and we will investigate your claim.
}

Copyright and moral rights for the publications made accessible in the public portal are retained by the authors and/or other copyright owners and it is a condition of accessing publications that users recognise and abide by the legal requirements associated with these

- Users may download and print one copy of any publication from the public portal for the purpose of private study or research.

- You may not further distribute the material or use it for any profit-making activity or commercial gain

If the publication is distributed under the terms of Article $25 \mathrm{fa}$ of the Dutch Copyright Act, indicated by the "Taverne" license above, 


\section{Skeletal muscle mitochondrial uncoupling, adaptive thermogenesis and energy expenditure Sjoerd A.A. van den Berg ${ }^{\mathrm{a}}$, Wouter van Marken Lichtenbelt ${ }^{\mathrm{b}}$, Ko Willems van Dijk ${ }^{\mathrm{a}}$ and Patrick Schrauwen ${ }^{\mathrm{b}}$}

\author{
${ }^{a}$ Department of Human Genetics, Leiden University \\ Medical Center, Leiden and ' ${ }^{\mathrm{D}}$ Department of Human \\ Biology, Maastricht Medical Center, Maastricht, \\ The Netherlands \\ Correspondence to Sjoerd A.A. van den Berg, PhD, \\ Leiden University Medical Center, Leiden, \\ The Netherlands \\ Tel: +3171 5269471; fax: +3171 5268285; \\ e-mail: svdberg@lumc.nl
}

Current Opinion in Clinical Nutrition and Metabolic Care 2011, 14:243-249

\begin{abstract}
Purpose of review
The prevalence of obesity is still increasing, despite obesity treatment strategies that aim at reducing energy intake. In addition to this, exercise programmes designed to increase energy expenditure have only a low efficiency and have generated mixed results. Therefore, strategies based on increasing energy expenditure via nonexercise means are currently under investigation. One novel strategy is the modulation of adaptive thermogenesis.

Recent findings

Among others, adaptive thermogenesis can be modulated by changing dietary composition, treatment with hormone mimetics as well as by cold exposure. In humans, a large part of the adaptive thermogenic response is, in addition to a putative role of brown adipose tissue, determined by the skeletal muscle mass via the process of mitochondrial uncoupling. Here, we describe the molecular processes involved in mitochondrial uncoupling, state-of-the-art techniques to measure mitochondrial uncoupling in vitro and in vivo, as well as the current strategies to mitochondrial uncoupling.
\end{abstract}

\section{Summary}

Data generated in rodents and humans implicate that increasing adaptive thermogenesis by increasing skeletal muscle mitochondrial uncoupling indeed elevates total energy expenditure and thus may provide a promising target for the treatment of obesity.

\section{Keywords \\ Curr Opin Clin Nutr Metab Care 14:243-249 \\ (C) 2011 Wolters Kluwer Health | Lippincott Williams \& Wilkins \\ 1363-1950}

adaptive thermogenesis, capsinoids, energy balance, uncoupling

\section{Introduction}

In this review we set out to give an overview of the latest developments in the field of increasing whole-body energy expenditure via adaptive thermogenesis. In particular, we focus on the contribution of skeletal muscle mitochondrial uncoupling to whole-body energy expenditure and adaptive thermogenesis. In addition, we review the latest developments regarding the application of increasing adaptive thermogenesis to fight the obesity epidemic and the possibilities to achieve this goal by modulation of skeletal muscle mitochondrial uncoupling.

In the modern Western society, the prevalence of obesity and obesity-related disorders are rising. The development of obesity is the result of a prolonged imbalance between energy intake and energy expenditure, and classically focus has been on reducing energy intake to correct this imbalance. However, although successful in the short term, the success rate of reducing energy intake in the long term is notoriously poor in humans, possibly due to the decrease in resting metabolic rate and exerciserelated energy expenditure as well as by promoting an unfavourable energy intake pattern $\left[1^{\bullet \bullet}, 2^{\bullet}, 3^{\bullet \bullet}\right]$. The reduction in metabolic rate could be a risk factor for weight regain in itself, although the contribution of energy intake and expenditure to weight gain are still under debate $\left[4^{\bullet}\right]$. Attempts to improve energy balance by exercise programmes have generated unclear results. Structured physical activity has been reported to increase total energy expenditure rates [5] but was found not to affect energy expenditure in another study [6]. Interestingly, Turner et al. $\left[7^{\bullet}\right]$ demonstrated that a 6 -month progressive exercise programme does result in weight loss but the absolute reduction is less than expected due to an increase in energy intake. This stresses the importance to measure and report both sides of the energy balance. Thus, despite the obvious social and health benefits, the limited potency for physical exercise programmes to increase total energy expenditure may be due to the fact that the caloric cost per 
time unit of common exercise types are typically low compared to the caloric intake [8]. An alternative, attractive approach would therefore be to induce sustained elevation of resting metabolic rate, especially because resting metabolic rate accounts for approximately 50$70 \%$ of total daily energy expenditure. Recent interest has focussed on adaptive thermogenesis, defined as 'a greater than predicted change in energy expenditure in response to changes in energy balance [9]', as a potential target for obesity therapy (reviewed in $\left[10^{\bullet \bullet}\right]$ ).

In addition to the classical adaptive thermogenic organ, the brown adipose tissue, skeletal muscle has been demonstrated to significantly contribute to adaptive thermogenesis. The capacity of skeletal muscle to contribute to whole-body energy expenditure can be related to the fact that muscle is composed of approximately $40 \%$ of the total body mass and to account for approximately $20-30 \%$ of the total resting oxygen uptake [11]. Furthermore, the contribution of proton leaks to resting metabolic rate can be as large as $20-50 \%$ [12], demonstrating the large potential of skeletal muscle to increase oxygen uptake. For example, the contribution of the skeletal muscle to diet-induced adaptive thermogenesis ranges between 35 and $67 \%$ [13]. In addition, up to $50 \%$ of adrenalin-induced thermogenesis was demonstrated to originate at the skeletal muscle level [14]. Mitochondrial uncoupling, the process whereby substrate oxidation is uncoupled from ATP production and directed towards heat loss (Fig. 1) is postulated to be an excellent target to

Figure 1 Schematic overview of skeletal muscle mitochondrial uncoupling

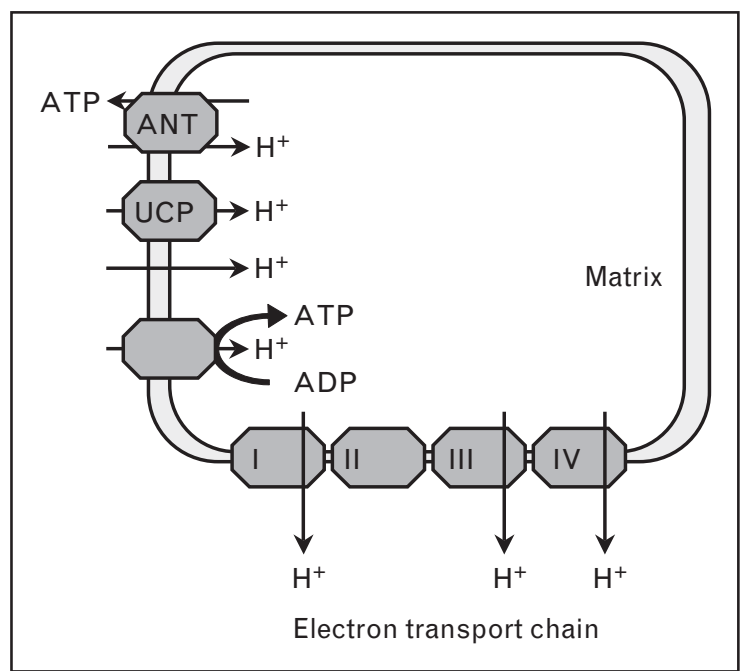

Oxygen consumption is uncoupled from ATP production by either a passive leak or UCP/ANT-mediated translocation of protons. ANT, adenine nucleotide translocator; ADP, adenosine diphosphate; ATP, adenosine triphosphate; UCP, uncoupling protein. Adapted with permission from [15].

\section{Key points}

- Increasing adaptive thermogenesis by elevating skeletal muscle mitochondrial uncoupling may provide a target for targeting obesity.

- An increase in energy intake may accompany the increase in energy expenditure upon increasing adaptive thermogenesis, stressing the importance to report changes on both sides of the energy balance.

- Nutritional induction of uncoupling, for example by capsinoids, are favourable in comparison to chemical uncoupling, for example using 2,4-dinitrophenol.

elevate whole-body energy expenditure [15]. This is mostly due to the high oxidative capacity of muscle, thereby allowing the upscaling of uncoupling-related energy expenditure. The other mechanisms that contribute to skeletal muscle adaptive thermogenesis (calcium cycling and protein turnover) may also provide potential targets, although the scaling possibilities are limited in comparison with uncoupling.

On the molecular level, mitochondrial uncoupling is the result of proton leak. In living cells, the metabolism of substrates such as fat, carbohydrate and proteins results in the production of reducing equivalents nicotinamide adenine dinucleotide (NADH) and flavin adenine dinucleotide (FADH2), which can be oxidized to $\mathrm{NAD}^{+}$, FAD and $\mathrm{H}^{+}$in a process called electron transfer or respiratory chain. The net transport of protons to the cytosolic side of the inner mitochondrial membrane generates a proton gradient across the mitochondrial membrane. When this proton gradient is high enough, protons flow back over the inner mitochondrial membrane through a so-called F0F1 complex and the energy thus generated is used by ATPase to transform ADP into ATP. In this way, substrate oxidation is coupled to the formation of ATP. However, the coupling between substrate oxidation and ATP formation is not $100 \%$ efficient; part of the generated proton gradient is lowered by proton leaks thereby dissipating energy as heat. It has been suggested that the contribution of proton leaks to resting metabolic rate can be as large as $20-50 \%$ [12]. The major protein involved in the process of skeletal muscle mitochondrial uncoupling is uncoupling protein 1 (UCP-1), which has its main function in brown adipose tissue [16 $6^{\circ}$. In other tissues, homologues of UCP-1 can be found (UCP-2 and UCP3 ), although their function with regard to energy homeostasis is still under debate. Interestingly, whereas UCP-2 has been demonstrated to be expressed in a variety of tissues, UCP-3 expression is mainly limited to the skeletal muscle and is thought to be only indirectly involved in adaptive thermogenesis $\left[17^{\bullet}\right]$. 


\section{Measurements of skeletal muscle mitochondrial uncoupling in vivo and in vitro}

The process of skeletal muscle mitochondrial uncoupling can be measured ex vivo using high-resolution respirometry and in vivo using magnetic resonance spectroscopy. In-vivo measurements of skeletal muscle uncoupling are based on ratio between tricarboxylic acid (TCA) cycle flux and rates of ATP synthase flux. In short, TCA cycle flux is measured combining information from ${ }^{31} \mathrm{P}$-MRS and NIRS to assess ATP production and oxygen consumption, respectively $\left[18,19^{\circ}\right]$. A second method is based on the combination of ${ }^{13} \mathrm{C}$ NMR (or MRS) and ${ }^{31} \mathrm{P}$ NMR (or MRS) [18]. This second approach is based on the ${ }^{13} \mathrm{C}$ NMR-based assessment of citric acid cycle activity and the ${ }^{31} \mathrm{P}$ NMR-based assessment of ATP synthesis. Both of these methods have been used extensively and have their own merits and drawbacks. One of the drawbacks is that the TCA:ATP ratio is taken as a measure of uncoupling but the ratio can be altered by both changes in TCA flux and/or changes in ATP flux. However, true mitochondrial uncoupling in a physiological sense is characterized by a lower efficiency of ATP production, but not a reduction (in other words, more substrate oxidation for the same amount of ATP production, as the latter is determined by demand, not by efficiency). Because the complete discussion of these techniques is beyond the scope of this review, we would like to refer the reviewer to the excellent and extensive review of these techniques $\left[20^{\bullet \bullet}\right]$.

High-resolution respirometry analysis involves the invitro measurement of oxygen consumption of isolated mitochondria under various circumstances. Oxygen consumption in the presence of substrate, inorganic phosphate and ADP is referred to as state 3 respiration. Under state 3 conditions, oxygen consumption is coupled to phosphorylation of ADP to ATP in addition to proton leak. On depletion of ADP (and thus without ATP synthesis), mitochondria maintain respiration at a much lower rate, referred to as state 4 respiration. In this case, respiration is uncoupled from ATP synthesis and the proton gradient is lowered by proton leak (Fig. 2) [21].

Using this method, it has been established that in humans skeletal muscle mitochondrial function is altered in the obese, insulin-resistant state, and thus that disturbances in skeletal muscle mitochondrial function may play a role in the propagation of these abnormalities [22,23]. In aged rats, it has been established that the degree of mitochondrial uncoupling was lower, and the optimal thermodynamic efficiency of the mitochondria was higher compared to young animals [24]. Interestingly, this may cause the more obesogenic phenotype of these animals, as elevated skeletal muscle mitochondrial proton leak has been indicated as a thermogenic mechanism favouring a lean phenotype [25]. Second, an obesogenic phenotype has been demonstrated to be associated with a low degree of mitochondrial coupling far before the development of obesity and/or insulin resistance in C57Bl/6 mice [26 $6^{\bullet \bullet}$. More specific, muscle mitochondrial uncoupling is higher in mice that have a high rate of energy intake which is insufficiently countered by an increase in energy expenditure. These data favour the hypothesis that increased mitochondrial oxidation, possibly through uncoupling, is a mechanism to protect the body from the deleterious effects of a positive energy balance.

\section{The contribution of elevated skeletal muscle mitochondrial uncoupling to whole-body energy expenditure}

As described before, the determination of skeletal muscle mitochondrial function can be performed in vivo or

Figure 2 Schematic representation of a respirometry analysis of mitochondria

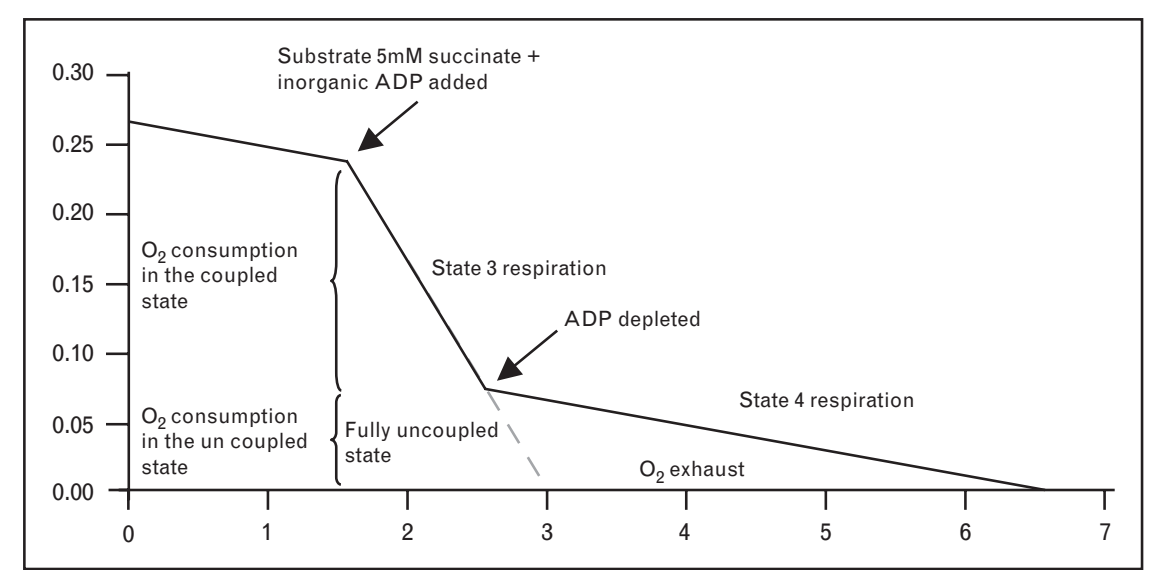

Adapted with permission from [21]. 
ex vivo. Measurements of whole-body energy expenditure, however, can only be performed in vivo, as it involves the complex interplay of all organs and systems in the body. When data from skeletal muscle mitochondrial function are later correlated with whole-body energy expenditure data it is important to keep some key points in mind. For example, since the number of subjects involved in a study is often too small to use advanced statistics [27], indirect calorimetry data are often corrected for total body mass in animal studies. In contrast, the human studies are almost always corrected for fat-free mass. Since the error introduced by either methods is not equal [ $\left.28^{\circ}\right]$, the outcome of a study may be biased and comparison may not be completely valid.

The contribution of higher rates of skeletal muscle mitochondrial uncoupling to thermogenesis has been demonstrated in various mouse models. Evidence for beneficial effects of skeletal muscle uncoupling comes from UCP1 muscle-specific overexpressing mice $\left[29^{\circ \bullet}\right]$. UCP1 overexpressing mice have a higher degree of whole-body energy expenditure, skeletal muscle mitochondrial uncoupling and are protected against high-fat diet induced obesity as well as glucose intolerance. In addition, UCP3 overexpression protects mice from high-fat diet induced obesity and insulin resistance [ $\left.30^{\bullet \bullet}\right]$. Although it has been suggested that the effects of UCP3 overexpression may be due to nonphysiological and nonregulated mitochondrial uncoupling [31], it still shows that the process of mitochondrial uncoupling lowers body weight.

In humans, convincing evidence for a role of skeletal muscle uncoupling to human energy expenditure comes from studies addressing the role of thyroid hormone. It is well known that thyroid hormone is involved in the regulation of human metabolic rate, and thyromimetics

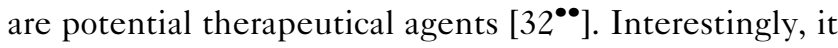
has been demonstrated that skeletal muscle mitochondrial metabolism is affected by circulating thyroid home

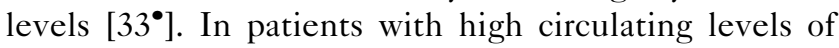
thyroid hormones, resting energy expenditure is significantly higher compared to controls. This was associated with high rates of muscle TCA cycle flux $(>75 \%)$, but not ATP synthesis, indicating a low mitochondrial coupling index $\left[34^{\bullet \bullet}\right.$. Similar results were found in triiodo-Lthyronine treated rats, in which energy coupling was decreased by approximately $60 \%$ after 10 days of treatment [35]. These data demonstrate that increasing skeletal muscle mitochondrial uncoupling is associated with resting energy expenditure. In addition to thyroid hormone, leptin has been demonstrated to regulate thermogenesis in muscle. Central leptin administration enhanced the postprandial response in muscle tissues in ovariectomized sheep, by increasing the amplitude and duration of the postprandial thermogenic response [36]. In part, this effect could be due to alterations in mitochondrial uncoupling, since leptin has been demonstrated to increase UCP1 mRNA expression in brown adipose tissue [37] although data on muscle are lacking. Together, these data clearly demonstrate that endocrine stimuli can enhance skeletal muscle mitochondrial metabolism, and thereby increase whole-body energy expenditure.

In addition to endogenous signals, exogenous stimuli have been demonstrated to affect total energy expenditure as well as skeletal muscle mitochondrial metabolism. In healthy subjects nonshivering thermogenesis was induced by mild cold exposure $\left(16^{\circ} \mathrm{C}\right)$. This induced total daily energy expenditure significantly by approximately $3 \%$ compared to subjects measured at room temperature. This increase in energy expenditure was linearly correlated with an increase in the rate of skeletal muscle mitochondrial uncoupling (state 4 respiration). No correlation was found between the increased energy expenditure and state 3 respiration, indicating that in vivo, the increase in energy expenditure was, at least in part, due to an increase in mitochondrial uncoupling [38]. Also, the postprandial processing of food has been demonstrated to induce energy expenditure, a process termed 'diet-induced thermogenesis'. In addition to total caloric intake $[39,40]$, the magnitude of diet-induced thermogenesis has been determined to be dependent on the macronutrient composition of the diet [41] and previous obesity status [42]. Interestingly, it has been demonstrated that maternal energy restriction, as well as postnatal high-fat feeding, alters mitochondrial oxidative capacity and respiratory coupling ratio in sheep [43], suggesting that dietary composition may be able to directly alter muscle mitochondrial function.

Early experiments, involving the chemical uncoupler 2,4-dinitrophenol (DNP) [44], already demonstrated the potential benefits of enhanced mitochondrial uncoupling on energy balance [ $\left.45^{\circ}\right]$, which can (at least in part) be explained by increased skeletal muscle mitochondrial uncoupling [46]. It is important to mention, however, that DNP has proven to be lethal $\left[47^{\circ}\right]$ and is therefore marked as an illegal weight loss agent. However, mitochondrial uncoupling as a target for obesity treatment is still under close scrutiny and has found new input in the nutrition field. Capsinoids (including the subclasses capsiate, dihydrocapsiate, and nordihydrocapsiate) are substances naturally present in chilli peppers. Recently, it has been demonstrated that treatment of healthy participants with $10 \mathrm{mg}$ of capsinoids results in an increased oxygen consumption and a lower respiratory quotient in healthy young men $\left[48^{\bullet}\right]$. However, another study using a similar set-up did not show this effect $\left[49^{\circ}\right]$. The main difference between the two studies was the exercise protocol and the time after ingestion of the capsinoid capsules at which respiratory gas exchange was measured. Galgani et al. $\left[49^{\bullet \bullet}\right]$ measured 
resting metabolic rate 45 min prior and 120 after ingestion, whereas Josse et al. [48 ${ }^{\bullet}$ assessed metabolic substrate utilisation at various timepoints from $30 \mathrm{~min}$ prior up to 150 after ingestion. These data indicate that the effects of capsinoids on metabolism and may in part be dependent on the activity status of the participant. To prevent the potential confounding effects of nutritional and exercise status prolonged experiments are advisable. Prolonged treatment of obese patients with $6 \mathrm{mg} / \mathrm{day}$ capsinoids resulted in a significant increase in fatty acid oxidation and a decrease in abdominal adiposity $\left[50^{\circ \bullet}\right]$. In part, the effect of capsinoid treatment may be due to an increase in mitochondrial uncoupling, as a 2-week treatment increased the levels of UCP-1 protein and mRNA in brown adipose tissue [51]. In another study, a single dose of capsinoids raised UCP-1 mRNA in brown adipose tissue and UCP-3 mRNA in skeletal muscle [51]. Longterm treatment, however, demonstrates a marked reduction in skeletal muscle UCP-3 levels $\left[52^{\bullet}, 53^{\bullet \bullet}\right]$, although this may reflect the improved obesity and insulin resistance phenotype rather than increased mitochondrial metabolism. Clearly, more studies are needed to investigate if the effects of capsinoids on thermogenesis are due to increased muscle mitochondrial uncoupling.

\section{Possible compensatory mechanisms to maintain energy balance upon increasing adaptive thermogenesis}

One caveat, however, remains the fact that weight maintenance is a matter of energy balance. As soon as energy expenditure is raised, and the balance becomes negative, the body may respond to that by increasing energy intake, and thus lead to weight regain [ $\left.54^{\circ}\right]$. The compensatory increase in energy intake has been demonstrated to be true, for example, in the described patients with high circulating levels of thyroid hormones. In addition to the increase in energy expenditure, energy intake was approximately $40 \%$ higher in patients compared to controls [34*0]. A second example is the UCP-1 overexpressing mouse. Body mass, as well as lean tissue mass, was lower but food intake was similar to wild-type controls. This indicates that, in addition to energy expenditure, food intake per gram of tissue mass was higher in UCP-1 overexpressing mice compared to wild-type controls $\left[30^{\bullet \bullet}\right.$. Third, treatment of rats with thyroid hormone (T4) led to a decrease in body weight, despite an increase in food intake by almost $20 \%$ [55 $]$. It is therefore adamant that energy intake is controlled if adaptive thermogenesis is used to target obesity.

\section{Conclusion}

In conclusion, it is clear that skeletal muscle mitochondrial uncoupling plays a role in the process of adaptive thermogenesis. Physiological endogenous as well as exogenous stimuli such as cold and leptin administration has been demonstrated to increase skeletal muscle uncoupling and to significantly affect total energy expenditure. In addition, because the upscaling possibility for skeletal muscle energy expenditure is large, increasing skeletal muscle mitochondrial uncoupling may be a potent target to fight the obesity epidemic.

\section{Acknowledgements}

This work was supported by grants from the Center of Medical Systems Biology (CMSB) and the Netherlands Consortium for Systems Biology (NCSB) established by The Netherlands Genomics Initiative/Netherlands Organization for Scientific Research (NGI/NWO).

\section{References and recommended reading \\ Papers of particular interest, published within the annual period of review, have been highlighted as: \\ - of special interest \\ - of outstanding interest \\ Additional references related to this topic can also be found in the Current World Literature section in this issue (p. 310).}

1 Rosenbaum M, Kissileff HR, Mayer LE, et al. Energy intake in weight-reduced -• humans. Brain Res 2010; 1350:95-102.

In this paper, Rosenbaum et al. give an excellent overview of the role of the central nervous system in energy intake in weight-reduced patients and the role of the adipocyte hormone leptin in this process.

2 Redman LM, Heilbronn LK, Martin CK, et al. Metabolic and behavioral - compensations in response to caloric restriction: implications for the maintenance of weight loss. PLoS One 2009; 4:e4377.

This paper describes the metabolic alterations associated with weight reduction, decreased energy expenditure and decreased physical activity index.

3 Pankevich DE, Teegarden SL, Hedin AD, et al. Caloric restriction experience - reprograms stress and orexigenic pathways and promotes binge eating. J Neurosci 2010; 30:16399-16407.

Here the authors clearly demonstrate the detrimental effects of stress on eating behaviour in a weight loss model. They show that stress induces binge eating on a high-fat diet, associated with a significant increase in the orexigenic hormones $\mathrm{MCH}$ and Orexin.

4 Bleich SN, Ku R, Wang YC. Relative contribution of energy intake and energy - expenditure to childhood obesity: a review of the literature and directions for future research. Int J Obes (Lond) 2010.

This review emphasises the need for more research and better methods to identify the relative contribution of energy intake and energy expenditure to obesity in the pediatric population. In our opinion, this also holds true for the adult population, in which data are scarce.

5 Hollowell RP, Willis LH, Slentz CA, et al. Effects of exercise training amount on physical activity energy expenditure. Med Sci Sports Exerc 2009; 41:16401644.

6 Goran MI, Poehlman ET. Endurance training does not enhance total energy expenditure in healthy elderly persons. Am J Physiol 1992; 263:E950-E957.

7 Turner JE, Markovitch D, Betts JA, Thompson D. Nonprescribed physical - activity energy expenditure is maintained with structured exercise and implicates a compensatory increase in energy intake. Am J Clin Nutr 2010; 92:1009-1016.

In this outstanding paper, Turner and colleages highlight the possible compensatory increase in energy intake as a confounding factor for of less-than-expected increased energy expenditure upon increased exercise-related energy expenditure.

8 Ainsworth BE, Haskell WL, Whitt MC, et al. Compendium of physical activities: an update of activity codes and MET intensities. Med Sci Sports Exerc 2000; 32:S498-S504.

9 Tremblay A, Chaput JP. Adaptive reduction in thermogenesis and resistance to lose fat in obese men. Br J Nutr 2009; 102:488-492.

10 Tseng YH, Cypess AM, Kahn CR. Cellular bioenergetics as a target for obesity -• therapy. Nat Rev Drug Discov 2010; 9:465-482.

In this paper, Tseng et al. demonstrate the potential for adaptive thermogenesis to affect weight maintenance. In particular, a reduction in thermogenesis is demonstrated to be a risk factor for the resistance to lose fat in obese men subjected to a weight-reducing programme. 
11 Zurlo F, Larson K, Bogardus C, Ravussin E. Skeletal muscle metabolism is a major determinant of resting energy expenditure. J Clin Invest 1990; 86:14231427.

12 Rolfe DF, Brown GC. Cellular energy utilization and molecular origin of standard metabolic rate in mammals. Physiol Rev 1997; 77:731-758.

13 Van Baak MA. Meal-induced activation of the sympathetic nervous system and its cardiovascular and thermogenic effects in man. Physiol Behav 2008; 94:178-186.

14 Astrup A, Bulow J, Madsen J, Christensen NJ. Contribution of BAT and skeletal muscle to thermogenesis induced by ephedrine in man. Am J Physiol 1985; 248:E507-E515.

15 Conley KE, Jubrias SA, Amara CE, Marcinek DJ. Mitochondrial dysfunction: impact on exercise performance and cellular aging. Exerc Sport Sci Rev 2007; 35:43-49.

16 Ribeiro MO, Bianco SD, Kaneshige M, et al. Expression of uncoupling protein

- 1 in mouse brown adipose tissue is thyroid hormone receptor-beta isoform specific and required for adaptive thermogenesis. Endocrinology 2010; $151: 432-440$.

In this paper, Ribeiro et al. clearly demonstrate that UCP-1-mediated uncoupling in brown adipose tissue is mediated by thyroid hormone. This may indicate that, at least in part, thyromimetic interventions affect energy homeostasis directly by affecting uncoupling.

17 Azzu V, Jastroch M, Divakaruni AS, Brand MD. The regulation and turnover of - mitochondrial uncoupling proteins. Biochim Biophys Acta 2010; 1797:785791.

In this review, a good overview of the putative role of the uncoupling protein isoforms 2 and 3 is given. Of special interest is the description of the possible indirect role of UCP-3 in whole-body energy expenditure.

18 Marcinek DJ, Schenkman KA, Ciesielski WA, Conley KE. Mitochondrial coupling in vivo in mouse skeletal muscle. Am J Physiol Cell Physiol 2004 286:C457-C463.

19 Amara CE, Shankland EG, Jubrias SA, et al. Mild mitochondrial uncoupling

- impacts cellular aging in human muscles in vivo. Proc Natl Acad Sci 2007, 104:1057-1062.

In this paper, the clinical application of 31P-MRS and NIRS is demonstrated. This provides a means to calculate mitochondrial uncoupling.

20 Lanza IR, Nair KS. Mitochondrial metabolic function assessed in vivo and in -. vitro. Curr Opin Clin Nutr Metab Care 2010; 13:511-517.

An overview of the current techniques that can be used to determine mitochondrial function in vivo and in vitro.

21 Schrauwen $\mathrm{P}$, Hoeks J, Hesselink MKC. Putative function and physiological relevance of the mitochondrial uncoupling protein-3: involvement in fatty acid metabolism? Prog Lipid Res 2006; 45:17-41

22 Mogensen $M$, Sahlin K, Fernstrom $M$, et al. Mitochondrial respiration is decreased in skeletal muscle of patients with type 2 diabetes. Diabetes 2007; 56:1592-1599.

23 Ritov VB, Menshikova EV, Azuma K, et al. Deficiency of electron transport chain in human skeletal muscle mitochondria in type 2 diabetes mellitus and obesity. Am J Physiol Endocrinol Metab 2010; 298:E49-E58.

24 lossa S, Mollica MP, Lionetti L, et al. A possible link between skeletal muscle mitochondrial efficiency and age-induced insulin resistance. Diabetes 2004; 53:2861-2866.

25 Monemdjou S, Hofmann WE, Kozak LP, Harper ME. Increased mitochondrial proton leak in skeletal muscle mitochondria of UCP1-deficient mice. Am J Physiol Endocrinol Metab 2000; 279:E941-E946.

26 Van den Berg SA, Nabben M, Bijland S, et al. High levels of whole-body

- energy expenditure are associated with a lower coupling of skeletal muscle mitochondria in C57BI/6 mice. Metabolism 2010; 59:1612-1618.

This is an extremely important paper in its field, as it clearly identifies a role for fat mass in the determination of whole-body energy expenditure.

27 Arch JRS, Hislop D, Wang SJY, Speakman JR. Some mathematical and technical issues in the measurement and interpretation of open-circuit indirect calorimetry in small animals. Int J Obes 2006; 30:1322-1331.

28 Kaiyala KJ, Morton GJ, Leroux BG, et al. Identification of body fat mass as a - major determinant of metabolic rate in mice. Diabetes 2010; 59:1657-1666. Here, the authors demonstrate the association between a higher degree of mitochondrial uncoupling and food intake..

29 Li B, Nolte LA, Ju JS, et al. Skeletal muscle respiratory uncoupling prevents

- diet-induced obesity and insulin resistance in mice. Nat Med 2000; 6:11151120.

Although the paper is somewhat older already, this represents the first concise study concerning muscle mitochondrial uncoupling and energy balance.

30 Choi CS, Fillmore JJ, Kim JK, et al. Overexpression of uncoupling protein 3 in

-. skeletal muscle protects against fat-induced insulin resistance. J Clin Invest 2007; 117:1995-2003.

In this proof-of-principle study, the authors demonstrate that the concept of mitochondrial uncoupling lowers body weight.
31 MacLellan JD, Gerrits MF, Gowing A, et al. Physiological increases in uncoupling protein 3 augment fatty acid oxidation and decrease reactive oxygen species production without uncoupling respiration in muscle cells. Diabetes 2005; 54:2343-2350.

32 Hirano $T$, Kagechika $H$. Thyromimetics: a review of recent reports and patents. Expert Opin Ther Pat 2010; 20:213-228.

This paper gives a good overview on the use and merits of thyromimetics in the field of obesity. The paper handles the current based thyromimetics and includes their potential tissue specificity.

33 Khushu S, Rana P, Sekhri T, et al. Bio-energetic impairment in human calf - muscle in thyroid disorders: a 31P MRS study. Magn Reson Imaging 2010; 28:683-689.

In this paper, Khushu et al. clearly demonstrate the effects of thyroid hormone status on oxidative metabolism in humans. In our opinion, the implications of this study should be seen in the value of thyromimetics in the field of obesity.

34 Mitchell CS, Savage DB, Dufour S, et al. Resistance to thyroid hormone is - $\quad$ associated with raised energy expenditure, muscle mitochondrial uncoupling, and hyperphagia. J Clin Invest 2010; 120:1345-1354.

In this paper, the potential role for thyroid hormone and hormone mimetics to increase skeletal muscle mitochondrial uncoupling is further strengthened by the observation that high circulating levels of thyroid hormone induce mitochondiral uncoupling.

35 Jucker BM, Dufour S, Ren J, et al. Assessment of mitochondrial energy coupling in vivo by $13 \mathrm{C} / 31 \mathrm{P}$ NMR. Proc Natl Acad Sci U S A 2000; 97:6880-6884.

36 Henry BA, Dunshea FR, Gould M, Clarke IJ. Profiling postprandial thermogenesis in muscle and fat of sheep and the central effect of leptin administration. Endocrinology 2008; 149:2019-2026.

37 Scarpace PJ, Nicolson M, Matheny M. UCP2, UCP3 and leptin gene expression: modulation by food restriction and leptin. J Endocrinol 1998; 159:349357.

38 Wijers SL, Schrauwen P, Saris WH, van Marken Lichtenbelt WD. Human skeletal muscle mitochondrial uncoupling is associated with cold induced adaptive thermogenesis. PLoS One 2008; 3:e1777.

39 D'Alessio DA, Kavle EC, Mozzoli MA, et al. Thermic effect of food in lean and obese men. J Clin Invest 1988; 81:1781-1789.

40 Kinabo JL, Durnin JV. Thermic effect of food in man: effect of meal composition, and energy content. Br J Nutr 1990; 64:37-44.

41 Westerterp KR. Diet induced thermogenesis. Nutr Metab (Lond) 2004; 1:5.

42 Rosenbaum M, Hirsch J, Gallagher DA, Leibel RL. Long-term persistence of adaptive thermogenesis in subjects who have maintained a reduced body weight. Am J Clin Nutr 2008; 88:906-912.

43 Jorgensen W, Gam C, Andersen JL, et al. Changed mitochondrial function by pre and/or postpartum diet alterations in sheep. Am J Physiol Endocrinol Metab 2009; 297:E1349-E1357.

44 Pinchot GB. The mechanism of uncoupling of oxidative phosphorylation by 2,4-dinitrophenol. J Biol Chem 1967; 242:4577-4583.

45 Caldeira da Silva CC, Cerqueira FM, Barbosa LF, et al. Mild mitochondrial

- uncoupling in mice affects energy metabolism, redox balance and longevity. Aging Cell 2008; 7:552-560.

The authours demonstrate that a mild induction of skeletal muscle uncoupling results in enhanced tissue respiratory rates, improved serological lipid and glucose profile and improved longevity.

46 Rohas LM, St-Pierre J, Uldry M, et al. A fundamental system of cellular energy homeostasis regulated by PGC-1alpha. Proc Natl Acad Sci U S A 2007; 104:7933-7938.

47 Bartlett J, Brunner M, Gough K. Deliberate poisoning with dinitro- phenol (DNP): an unlicensed weight loss pill. Emerg Med J 2010; 27:159-160.

Together with another study $\left[4^{\circ}\right]$, it represents the first well performed human metabolism studies using capsinoids. Interestingly, although the results protocol followed in both studies are highly similar, the results are contradictory.

48 Josse AR, Sherriffs SS, Holwerda AM, et al. Effects of capsinoid ingestion on - energy expenditure and lipid oxidation at rest and during exercise. Nutr Metab (Lond) 2010; 7:65.

Together with another study [49*0], it represents the first well performed human metabolism studies using capsinoids. Interestingly, although the results protocol followed in both studies are highly similar, the results are contradictory.

49 Galgani JE, Ryan DH, Ravussin E. Effect of capsinoids on energy metabolism -. in human subjects. Br J Nutr 2010; 103:38-42.

In our opinion, the presented paper is one of the most valuable tools and possibilities to warn the public for the potential deadly effects of DNP, a chemical mitochondrial uncoupler. 
50 Snitker S, Fujishima Y, Shen $\mathrm{H}$, et al. Effects of novel capsinoid treatment - on fatness and energy metabolism in humans: possible pharmacogenetic implications. Am J Clin Nutr 2009; 89:45-50.

This study represents the first dataset concerning the long-term effects of capsinoid treatment on energy balance.

51 Masuda Y, Haramizu S, Oki K, et al. Upregulation of uncoupling proteins by oral administration of capsiate, a nonpungent capsaicin analog. J Appl Physiol 2003; 95:2408-2415.

52 Faraut B, Giannesini B, Matarazzo V, et al. Capsiate administration results in

- an uncoupling protein-3 downregulation, an enhanced muscle oxidative capacity and a decreased abdominal fat content in vivo. Int J Obes (Lond) 2009; 33:1348-1355.

In this paper, long-term capsiate treatment leads to a reduction in muscular UCP-3 content but increased oxidative capacitiy. This further strengthens the possible use of capsiate in obesity treatment.
$53 \mathrm{Kim}$ DH, Joo Jl, Choi JW, Yun JW. Differential expression of skeletal muscle - proteins in high-fat diet-fed rats in response to capsaicin feeding. Proteomics 2010; 10:2870-2881.

In this paper, the authors demonstrate that capsaicin treatment results in decreased weight gain in rats. In addition, by proteomics they demonstrate that capsaicin treatment results in augmented AMPK-ACC-malonyl-CoA signalling.

54 Rosenbaum M, Leibel RL. Adaptive thermogenesis in humans. Int J Obes - (Lond) 2010; 34 (Suppl 1):S47-S55.

In this paper, Rosenbaum and Leibel discuss the pivotal role of adaptive thermogenesis in weight maintenance in patients who underwent weight loss.

55 Klieverik LP, Coomans CP, Endert E, et al. Thyroid hormone effects on whole- body energy homeostasis and tissue-specific fatty acid uptake in vivo. Endocrinology 2009; 150:5639-5648.

This paper is only one of many examples in which the an elevation of energy expenditure is associated with an increase in energy intake, further stressing the need of the raportation of both sides of the energy balance in metabolic studies. 